\title{
La relación entre el principio de legalidad en derecho penal internacional y la tipificación internacional de los crímenes de lesa humanidad: una perspectiva histórica
}

\author{
José Augusto Pacheco de Freitas*
}

\section{RESUMEN}

En este artículo se revisan los procesos de consolidación del principio de legalidad y de tipificación de los crímenes de lesa humanidad en el ámbito del derecho penal internacional desde una perspectiva histórica. Para ello, se repasa el desarrollo de ambos procesos, partiendo del Tribunal de Núremberg hasta culminar con la consagración del principio de legalidad en una serie de tratados universales de protección de derechos humanos suscritos entre las décadas de 1960 y 1980 y con la tipificación internacional de los crímenes de lesa humanidad en los estatutos de los Tribunales Penales Internacionales para la ex-Yugoslavia y para Ruanda y el Estatuto de Roma de la Corte Penal Internacional.

Palabras clave: Derecho penal internacional, principio de legalidad, nullum crimen sine lege, nulla poena sine lege, crímenes de lesa humanidad, Tribunal Militar Internacional de Núremberg, Tribunal Penal Internacional para la ex-Yugoslavia, Tribunal Penal Internacional para Ruanda, el Estatuto de Roma de la Corte Penal Internacional, derechos humanos

\footnotetext{
* Primer Secretario en el Servicio Diplomático de la República del Perú, presta funciones en la Embajada del Perú en el Reino Unido. Es magíster en Diplomacia y Relaciones Internacionales por la Academia Diplomática del Perú y en Relaciones Internacionales y Diplomacia por la Escuela Diplomática de Madrid. Ha completado estudios de maestría en Historia por la Universidad Torcuato di Tella, Buenos Aires, y de doctorado en Ciencias Jurídicas por la Pontificia Universidad Católica Argentina. El presente artículo es parte de la investigación para la elaboración de su tesis doctoral y las opiniones expresadas en él lo son solo a título personal. El autor desea agradecer los valiosos comentarios de Ada Inés Sánchez Echevarría para la preparación de este trabajo. Correo electrónico: joseapachecodefreitas@gmail.com
}

iD https://orcid.org/0000-0003-4069-9429 
The relation between the principle of legality in international criminal law and the international criminalisation of crimes against humanity in historical perspective

\section{Abstract}

This article reviews the processes of consolidation of the principle of legality and of the criminalisation of crimes against humanity in international criminal law from a historical perspective. It starts with the Nuremberg Tribunal of 1945 and then traces the development of these two processes side-by-side: the enshrinement of the principle of legality in a series of universal treaties protecting human rights between the 1960s and the 1980s and the criminalisation of crimes against humanity in the Statutes for the International Criminal Tribunals for the former Yugoslavia and for Rwanda and in the Rome Statute of the International Criminal Court.

Keywords: International criminal law, principle of legality, nullum crimen sine lege, nulla poena sine lege, crimes against humanity, Nuremberg International Military Tribunal, International Criminal Tribunal for the former Yugoslavia, International Criminal Tribunal for Rwanda, Rome Statute of the International Criminal Court, human rights

\section{Introducción}

Las reflexiones que se presentan en este trabajo tienen su origen en los debates en clase durante mis estudios de doctorado sobre las sentencias de la Corte Suprema de Justicia de la Nación argentina en los casos Arancibia Clavel y Simón ${ }^{1}$, en las cuales el tribunal sostuvo que conductas cometidas en la década de 1970, pero juzgadas en 2004 y 2005, constituían crímenes de lesa humanidad. La parte sustancial de estas decisiones no se fundamentó jurídicamente en las normas nacionales argentinas, sino que se basó en una mención inorgánica y poco técnica de normas de derecho internacional, aplicando retroactivamente la tipificación penal internacional para los crímenes de lesa humanidad — adoptada en el Estatuto de Roma de la Corte Penal Internacional de 1998-, y, por consiguiente, la imprescriptibilidad prevista en la Convención sobre la imprescriptibilidad de los crímenes de guerra y de los crímenes de lesa humanidad —a la cual Argentina adhirió en 2003-.

No es mi intención hacer un comentario de modo especifico sobre los fallos mencionados, sino solo presentar elementos que permitan al lector evaluar de modo general la aplicación retroactiva del tipo penal de los crímenes de lesa humanidad en el derecho penal internacional a conductas previas a su tipificación ${ }^{2}$. Una conclusión sobre

\footnotetext{
${ }^{1}$ Corte Suprema de Justicia de la Nación de la República Argentina, Arancibia Clavel, Enrique Lautaro, s/ homicidio calificado y asociación ilícita y otros, sentencia del 24 de agosto de 2004; y Corte Suprema de Justicia de la Nación de la República Argentina, Simón, Julio Héctor y otros, s/ privación ilegítima de la libertad, etc., sentencia del 14 de junio de 2005.

2 Para comentarios, veáse: Garibian, 2010, pp. 197-215; Legarre, 2006, pp. 723-732.
} 
si dicha aplicación retroactiva es deseable debido a que se trató de conductas que formaron parte de aparatos de represión estatal vinculados a regímenes dictatoriales militares excede las consideraciones jurídicas que animan esta investigación y corresponde a los ámbitos de la filosofía del derecho, la moral, la sociología, la política criminal, entre otros, por lo que no será abordada en este artículo.

Esta mirada, que podría llamarse formalista, o incluso positivista, se inspira en lo escrito por Brownlie hace ya más de cincuenta años: «if 'formalism' be regarded as a synonym for resort to legal method then of course one need not shrink from it» (Brownlie, 1963, p. vii). En el análisis y las conclusiones que se presentan en este artículo se procurará aplicar el método legal a conductas que despiertan comprensibles pasiones, al involucrar atrocidades lamentables que es deseable prevenir y sancionar. Con todo, sostengo que, desde el Estado de derecho y la democracia liberal, para una persecución penal conforme a derecho y respetuosa de las garantías del debido proceso es necesario solucionar previamente el dilema de si los fiscales y jueces deben o no respetar siempre el principio de legalidad, expresado en las máximas complementarias nullum crimen sine lege y nulla poena sine lege.

Es posible sostener que en Arancibia Clavel y en Simón el alto tribunal argentino partió de la premisa de que este dilema ya estaba solucionado, procurando justificar su posición en normas de derecho internacional con carácter de ius cogens que consideraba indiscutiblemente aplicables a los hechos cometidos por los imputados en la década de 1970. Por ello, el objetivo fundamental de este trabajo es mostrar que este dilema no ha sido superado y que la persecución de atrocidades cometidas antes de la tipificación de los crímenes de lesa humanidad supone inherentemente un conflicto con el principio de legalidad.

En este trabajo no se busca establecer si se puede, o si se debe, perseguir retroactivamente conductas que constituirían crímenes de lesa humanidad para el derecho penal internacional contemporáneo. Bajo la premisa de que con anterioridad a los tribunales ad hoc — con competencias acotadas temporal y geográficamente- y a la Corte Penal Internacional — que sin duda alguna no ejerce jurisdicción retroactivamente- no existían tribunales internacionales competentes para conocer sobre dichos crímenes, esa es una decisión que corresponde a cada sistema jurídico nacional, con sus propios principios y normas constitucionales y penales y con su propia estructura jurisdiccional ${ }^{3}$.

\footnotetext{
3 A modo de ejemplo, es de particular relevancia la experiencia alemana, presentada en: Arnold, Karsten y Kreicker, 2003.
} 
Con esas precisiones, en este artículo se revisarán desde una perspectiva histórica los procesos de consolidación del principio de legalidad y de tipificación de los crímenes de lesa humanidad en el ámbito del derecho penal internacional. Para ello se parte de la situación de ambas instituciones hacia 1945, en los procesos penales del Tribunal Militar Internacional de Núremberg, para luego repasar su desarrollo en paralelo: de un lado, la consagración del principio de legalidad en una serie de tratados universales de protección de derechos humanos suscritos entre las décadas de 1960 y 1980 y, del otro, la tipificación internacional de los crímenes de lesa humanidad en los estatutos de los tribunales penales internacionales para la ex-Yugoslavia y Ruanda así como en el Estatuto de Roma de la Corte Penal Internacional.

La relevancia de este trabajo es doble. En primer lugar, se busca dar mayor claridad a cómo operaron ambas instituciones en Núremberg, donde el Tribunal Militar Internacional no podría haber rechazado el principio de legalidad porque este no era todavía "rechazable», al no ser todavía exigible en el ámbito internacional. Por ello, que fuera considerado solo como un "ideal de justicia» podría tener asidero. Asimismo, el tribunal no se pronunció sobre la eventual aplicación del principio de legalidad a los crímenes de lesa humanidad, sino únicamente a los crímenes contra la paz y los crímenes de guerra. En segundo lugar, partiendo de la premisa de que en las décadas siguientes a los procesos de Núremberg el principio de legalidad devino parte del núcleo duro del derecho internacional de los derechos humanos, se identificarán las dificultades para fundamentar jurídicamente la persecución de presuntos crímenes de lesa humanidad cometidos antes del establecimiento de los estatutos de los tribunales para la ex-Yugoslavia y para Ruanda.

La estructura de este ensayo está dividida en dos secciones. En la primera se hará un desarrollo histórico del principio de legalidad en el derecho penal internacional, mientras que en la segunda se hará lo propio con la tipificación de los crímenes de lesa humanidad. En una sección adicional se presentarán las conclusiones correspondientes.

\section{Desarrollo histórico del principio de legalidad en el derecho penal internacional}

La raison d'être de la máxima nullum crimen sine lege praevia es que, para que haya un delito, se requiere de una ley previa, por lo que un individuo solo puede ser procesado — y, eventualmente, condenado - por conductas que, al momento de ser cometidas, ya eran consideradas como criminales por la ley. Por ello, la máxima constituye un límite al poder punitivo del Estado, en salvaguardia de los derechos de la persona, para lo que es complementada por el aforismo nulla poena sine lege praevia, conforme al cual la sanción — pena — que corresponde a la conducta criminal debe también haber 
sido establecida previamente por la ley. Ambas máximas componen el principio de legalidad, «un elemento fundamental de los sistemas de justicia penal respetuosos del Estado de derecho y del debido proceso» (Broomhall, 2016, p. 950, pár. 1).

Sin embargo, es importante diferenciar entre las dos máximas (Schabas, 2000, p. 522). Para fines de este trabajo se distinguirá entre el principio nullum crimen, que requiere que una conducta haya sido considerada criminal al momento de su ejecución para que sea punible; y el principio nulla poena, que requiere una variedad de aspectos relativos a la sanción por la conducta criminal, tales como que la pena a aplicar haya sido establecida con anterioridad a la punición de la conducta; que la pena efectivamente aplicada no sea más grave que la prevista; y, que, de ser el caso, se tome en cuenta la retroactividad benigna para el imputado.

El principio de legalidad goza de una amplia aceptación en la gran mayoría de sistemas jurídicos nacionales, especialmente en los de common law y en los romanogermánicos ${ }^{4}$. Asimismo, está recogido expresamente en los principales instrumentos internacionales en materia de derechos humanos, que prohíben tanto la persecución de conductas que no eran delitos al momento de su ejecución como la imposición de penas que no estuvieran previstas con anterioridad a los hechos. Entre ellos, cabe mencionar el artículo 15.1 del Pacto Internacional sobre Derechos Civiles y Políticos, el artículo 7.1 de la Convención Europea de Derechos Humanos, el artículo 9 de la Convención Americana de Derechos Humanos y el artículo 7.2 de la Carta Africana de Derechos Humanos y de los Pueblos. En el mismo sentido, se encuentra previsto en el artículo 11.2 de la Declaración Universal de los Derechos Humanos.

Asimismo, el principio de legalidad ha sido llamado, en sentido figurado, «la Carta Magna del criminal», pues asegura el derecho del acusado a ser sancionado solo conforme a lo previsto en la ley, dentro de los límites fijados por ella (von Liszt, 2007, p. 1010). Además, el principio de legalidad ha sido considerado recurrentemente en los tratados de derechos humanos mencionados como una norma indero-

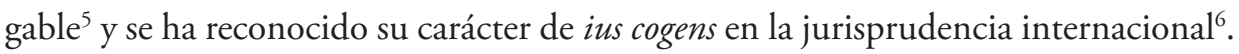

\footnotetext{
4 Este trabajo no es un estudio de derecho comparado, sino que se concentra en los sistemas de common law y romano-germánico, tradiciones jurídicas que han tenido un rol preeminente en el desarrollo del derecho penal internacional. Esta posición sigue lo planteado por el juez Cassese: «international criminal procedure does not originate from a uniform body of law. It substantially results from an amalgamation of two different legal systems, that obtaining in common-law countries and the system prevailing in countries of civil-law» (Tribunal Penal Internacional para la ex-Yugoslavia, Prosecutor c. Erdemović, sentencia del 7 de octubre de 1997, opinión disidente del juez Cassese, pár. 4).

5 Artículo 4.2 del Pacto Internacional sobre Derechos Civiles y Políticos, artículo 15.2 de la Convención Europea de Derechos Humanos y artículo 27.2 de la Convención Americana de Derechos Humanos.

6 Tribunal Europeo de Derechos Humanos, Maktouf y Damjanović c. Bosnia y Herzgovina, sentencia del 19 de julio de 2013, opinión concurrente del juez Pinto de Albuquerque, p. 46, pár. 9; y Tribunal Especial para el Líbano, Prosecutor c. Ayyash, sentencia del 16 de febrero de 2011, pp. 45-46, pár. 76.
} 
Adicionalmente, es parte del núcleo duro del derecho internacional de los derechos humanos (Schabas, 2015, p. 328), por lo que los Estados no pueden dejar de aplicarlo ni acordar entre sí disposiciones que lo contravengan.

Es pertinente recordar que el principio de legalidad estuvo presente desde el hito fundacional del derecho penal internacional, i.e. desde el establecimiento del Tribunal Militar Internacional de Núremberg (en adelante, el TMI), el cual debió analizar en 1945 si el principio de legalidad era una defensa válida para los jerarcas nazis. El TMI concluyó, respecto de los crímenes contra la paz y los crímenes de guerra, que los imputados debian saber que violaban el derecho internacional vigente y que, por lo tanto, eran susceptibles de ser juzgados y eventualmente condenados (Tribunal Militar Internacional, 1947, vol. 1, p. 219). Por ello, en lugar de evaluar si los crímenes contra la paz y los crímenes de guerra eran crímenes internacionales — pese a que para entonces no estaban recogidos como tales en ningún tratado ni norma consuetudinaria-, el TMI consideró que a los acusados se les imputaba una conducta que ya era criminal antes del establecimiento del propio Tribunal, sin explicar cuál era el fundamento jurídico para ello (Raimondo, 2008, p. 78). Adicionalmente, el TMI señaló, respecto de la naturaleza del principio de legalidad:

In the first place, it is to be observed that the maxim nullum crimen sine lege is not a limitation of sovereignty, but is in general a principle of justice. To assert that it is unjust to punish those who in defiance of treaties and assurances have attacked neighboring states without warning is obviously untrue, for in such circumstances the attacker must know that he is doing wrong, and so far from it being unjust to punish him, it would be unjust if his wrong were allowed to go unpunished. (Tribunal Militar Internacional, 1947, 1, p. 219)

Este pasaje justifica que no se tuviera en cuenta la aplicación de la máxima nullum crimen sine lege praevia porque esta era solo un principio de justicia, sin la fuerza jurídica suficiente para limitar la soberanía de los Estados que establecieron el TMI. Bajo esta noción, se podría afirmar que, conforme a la argumentación del TMI, hacia 1945 se podían imputar delitos en el ámbito del derecho penal internacional por conductas no previstas como criminales con anterioridad, sin que los imputados pudieran alegar una defensa sobre la base del principio de legalidad.

Como ha señalado Gallant (2009, p. 1), la citada aseveración del TMI tiene un aura de cinismo, al asumir que los jueces podían ignorar principios de justicia al servicio de las potencias soberanas que establecieron el Tribunal. Barboza añade que se trata de otra manera de decir que no existía una norma en derecho internacional que limitara el poder de los Estados soberanos de aplicar retroactivamente el derecho penal internacional si estimasen conveniente hacerlo, explicación más razonable que la empleada por el TMI. En efecto, aun cuando en la experiencia comparada de 1945 
el carácter constitucional del principio de legalidad impedía la aplicación retroactiva de la norma penal en varios sistemas jurídicos nacionales, en el ámbito internacional no existía para entonces tal freno a la soberanía estatal (Barboza, 1999, p. 117, y Lamb, 2002, p. 734). En ese sentido, la soberanía de los Estados y la falta de pedigrí jurídico del principio de legalidad en el ámbito internacional sustentaban la noción de que la propia voluntad estatal era suficiente para adoptar una tipificación penal que operara retroactivamente, como acordaron los Estados que suscribieron la Carta del Tribunal de Núremberg.

En todo caso, se debe recordar una vez más que el pasaje citado se refería solo a los crímenes contra la paz y los crímenes de guerra, que para el TMI eran conductas que ya eran consideradas como contrarias a derecho, i.e. antijurídicas en términos penales. Sin embargo, no se podía decir lo mismo de los crímenes de lesa humanidad. Como señala Lamb: «[T]he IMT tackled the issue of ex post facto law only with regard to crimes against peace (in particular aggression) whereas it did not pronounce at all upon the no less delicate question of whether or not crimes against humanity constituted a new category of offences» (Lamb, 2002, p. 737).

Este es un punto que no suele ser enfatizado y de hecho hay comentaristas que aplican el dictum del TMI sobre el principio de legalidad como un "principio de justicia» a todos los crímenes internacionales. En rigor, respecto a la aplicación retroactiva de la tipificación de los crímenes de lesa humanidad, el argumento del TMI es muy difícil de sostener y parece más bien que efectivamente aplicó «derecho nuevo» (Lamb, 2002, p. 736).

Las principales críticas a los tribunales que juzgaron como crímenes internacionales las atrocidades cometidas por los funcionarios de las potencias del Eje en la Segunda Guerra Mundial fueron que el contenido de los crímenes fue tipificado ex post facto, sin aplicar el principio de legalidad; que los tribunales fueron establecidos para que los vencedores en la guerra juzgaran a los vencidos ${ }^{7}$; y que se ignoraron los crímenes cometidos por los Aliados ${ }^{8}$. Si bien en general se reconoce a estos tribunales el mérito de contribuir a la persecución y sanción de conductas que sin ninguna duda conmocionaron a la humanidad en su conjunto — la definición canónica de crímenes de lesa humanidad-, su legado como derecho —en general — y como derecho penal internacional —en especial— es bastante más cuestionable. Las críticas se produjeron

\footnotetext{
7 "[T]he Nuremberg trials, which have been criticised from some quarters as an attempt to apply retroactively 'victors' justice' in an outrageous disregard for the principle of legality with regard to both crimes and punishment» (Catenacci, 2003, II, p. 88).

8 A modo de ejemplo, no he hallado referencias a procesos penales por crímenes de guerra ni crímenes de lesa humanidad por los bombardeos sobre Dresde, el aniquilamiento de funcionarios civiles y militares rendidos en Katyn y el empleo de bombas atómicas en Hiroshima y Nagasaki.
} 
incluso contemporáneamente, tanto en los propios tribunales ${ }^{9}$ como en la doctrina (Schwelb, 1946, pp. 178-226).

Por su parte, en su defensa de las consideraciones del TMI sobre el principio de legalidad, Kelsen se refirió a este como una norma más bien relativa, abierta a varias excepciones, y sostuvo que «la irretroactividad del derecho aplicado» a los imputados difícilmente podía ser considerada como absolutamente incompatible con la justicia (Kelsen, 1947, p. 165). Vale decir, incluso al justificar la aplicación del derecho penal internacional por el TMI, Kelsen no pudo evitar referirse a la aplicación retroactiva de normas emitidas con posterioridad (ex post facto) a las conductas delictivas y, adicionalmente, expresó que en 1945 el principio de legalidad era todavía una norma relativa. Ello es coherente con lo planteado en este artículo sobre la posterior consolidación, recién en las décadas siguientes, del principio de legalidad como una norma internacional y, además, parte del núcleo duro del derecho internacional de los derechos humanos.

Luego de los procesos de Núremberg, la cronología de la adopción del texto y la entrada en vigor de los principales tratados de derechos humanos sugiere que el principio de legalidad ya era una norma consuetudinaria por lo menos desde la década de 1970. Entre las décadas de 1950 y 1970 fue incluido en la Convención Europea de Derechos Humanos, adoptada el 4 de noviembre de 1950 y en vigor desde el 1 de enero de 1953; en el Pacto Internacional sobre Derechos Civiles y Políticos, adoptado el 16 de diciembre de 1966 y en vigor desde el 23 de marzo de 1976; y en la Convención Americana de Derechos Humanos, adoptada el 22 de noviembre de 1969 y en vigor desde el 8 de julio de 1978. Adicionalmente, había sido incluido con anterioridad en la Declaración Universal de los Derechos Humanos, adoptada el 10 de diciembre de 1948. De este modo, sobre la base de su inclusión en los instrumentos internacionales mencionados - amplia evidencia de práctica estatal y de que la mayoría de Estados lo consideraba obligatorio-, el principio de legalidad habría adquirido además el carácter de norma consuetudinaria de alcance general (Lamb, 2002, p. 736), por lo que sería aplicable a la totalidad de Estados que integran la sociedad internacional. Por ello, Schabas sostiene que el enfoque flexible con el cual se abordó el principio de legalidad en Núremberg devino en una prohibición más rígida y absoluta a partir de su incorporación en dichos tratados de derechos humanos (Schabas, 2015, p. 330).

Más adelante, casi cincuenta años después de los procesos de Núremberg, en su reporte al Consejo de Seguridad de la ONU para el establecimiento del Tribunal Penal Internacional para la ex-Yugoslavia, el secretario general de la ONU consideró

\footnotetext{
9 Ver los comentarios sobre las opiniones disidentes en el TMI para el Lejano Oriente del juez Bernard Rölling, en Barboza, 1999, p. 119; y del juez Radhabinod Pal, en: Gallant, 2009, pp. 1-2.
} 
que el principio nullum crimen sine lege praevia establecía exigencias a los Estados y a la organización, al afirmar que:

[T] he application of the principle nullum crimen sine lege requires that the international tribunal should apply rules of international humanitarian law which are beyond any doubt part of customary law so that the problem of adherence of some but not all States to specific conventions does not arise. (ONU, 1993, pár. 34; énfasis añadido)

Posteriormente, en los artículos 22 y 23 del Estatuto de Roma de la Corte Penal Internacional (en adelante, la CPI), adoptado el 17 de julio de 1998 y en vigor desde el 1 de julio de 2002, se incorporó expresamente el principio de legalidad, cuya importancia fue enfatizada en todas las etapas de la negociación del acuerdo. Al respecto, hubo consenso en que los delitos sujetos a la jurisdicción de la Corte debían ser definidos con la «claridad, precisión y especificidad requeridas por el derecho penal en concordancia con el principio de legalidad»(ONU, 1996, p. 16, pár. 52). De igual manera, hubo una amplia coincidencia en que los principios fundamentales de derecho penal aplicables a los delitos sancionables bajo el Estatuto debían estar claramente enumerados en el mismo, «de conformidad con el principio de legalidad» (ONU, 1996, p. 41, pár. 180 y p. 42, pár. 185). Barboza menciona al respecto: "this cardinal principle of liberal penal law is firmly established in the Convention» (Barboza, 1999, p. 148). De esta manera, el desarrollo del principio de legalidad desde Núremberg hasta la CPI, pasando por las múltiples normas de derechos humanos enumeradas en los párrafos precedentes, permite marcar una clara diferencia entre su situación jurídica actual y la de 1945 (Barboza, 1999, p. 148).

A nivel jurisprudencial es de particular importancia la casuística del Tribunal Europeo de Derechos Humanos (en adelante, «el TEDH») sobre la aplicación del principio de nullum crimen sine lege, bajo la premisa de que todo delito debe estar claramente definido en la legislación, conforme al artículo 7 de la Convención Europea de Derechos Humanos. A inicios de la década de 1990 el TEDH consolidó un criterio interpretativo, el cual ha venido manteniendo regular y sostenidamente, que parte de la constatación de que no siempre es posible que la letra de la ley contemple comprehensivamente la conducta ilícita, por lo que para satisfacer el principio de legalidad será suficiente que se cumpla con dos requisitos cualitativos: que el individuo tenga acceso al texto de la tipificación y a su interpretación por los tribunales (accesibilidad) y que las normas estén formuladas con la precisión necesaria para que pueda prever razonablemente (Schabas, 2015, p. 341) qué conductas son ilícitas (previsibilidad). Estos dos requisitos — accesibilidad y previsibilidad — han sido considerados en una abundante y coherente jurisprudencia por el $\mathrm{TEDH}^{10}$ y constituyen un estándar

\footnotetext{
${ }^{10}$ Entre varias otras sentencias del TEDH, Margareta y Roger Andersson c. Suecia, sentencia del 25 de febrero de 1992, pár. 75; Kokkinakis c. Grecia, sentencia del 25 de mayo de 1993, pár. 52; S. W. c. Reino Unido, sentencia del
} 
ampliamente considerado a nivel internacional como representativo del examen que se debe realizar para determinar si la persecución estatal ha cumplido con el principio de legalidad ${ }^{11}$.

El estándar de accesibilidad y previsibilidad, producto de la interpretación del TEDH sobre los alcances del principio de legalidad, fue cobrando forma durante la década de 1990, en un proceso paralelo al de la consolidación de dicho principio como parte del núcleo duro del derecho internacional de los derechos humanos y al de la tipificación de los crímenes de lesa humanidad. Es importante mencionar que el estándar de accesibilidad y previsibilidad no parece ser una barrera muy alta para la persecución penal, sino que más bien busca ponerse en el lugar del imputado para considerar, razonablemente, si se encontraba o no en aptitud de conocer que las conductas por las que se lo procesa eran delictivas al momento de su comisión. De hecho, para Schabas (2015, p. 330), la casuística del TEDH «refleja el espíritu de los jueces de Núremberg».

Toda vez que el estándar de accesibilidad y previsibilidad no supone un umbral difícil de superar, parece razonable emplearlo como un parámetro para evaluar analíticamente - pero no jurídicamente- si la persecución de casos previos a la década de 1990 es respetuosa del derecho del imputado a solo ser procesado y condenado por conductas que la ley ya consideraba criminales al momento de su comisión. De esa manera, el punto inicial de la indagación ya no será «la claridad y precisión de la norma», sino más bien analizar desde el punto de vista de los imputados si «debían saber, y si podrían haber sabido» que cometían un delito (Arnold, Karsten y Kreicker, 2003, p. 86).

Volviendo a los casos Arancibia Clavel y Simón, un aspecto fundamental que la Corte Suprema de Justicia de la Nación argentina debió considerar fue si, al momento de cometer los presuntos crímenes, los imputados se encontraban en aptitud de conocer razonablemente que sus conductas constituirían crímenes de lesa humanidad, susceptibles de ser perseguidas como crímenes internacionales, y no meros delitos en sede nacional, sujetos a la normativa sustantiva y procesal correspondiente. A modo de ejemplo, es claro que los perpetradores de homicidios conocen que su conducta es criminal, ilícita, pero parece difícil sostener que antes de la década de 1990 podían

\footnotetext{
22 de noviembre de 1995, pár. 35-36; C.R. c. Reino Unido, sentencia del 22 de noviembre de 1995, pár 34; Cantoni c. Francia, sentencia del 11 de noviembre de 1996, pár. 29-30; y E.K. c. Turquía, sentencia del 7 de febrero de 2002, pár. 51.

${ }^{11} \mathrm{Al}$ respecto, Ambos (2013, p. 75) menciona las referencias del Tribunal Penal Internacional para la ex-Yugoslavia a los requisitos de accesibilidad y previsibilidad en Prosecutor c. Vasiljevic, sentencia del 29 de noviembre de 2002, pár. 193; Prosecutor c. Hadzihasanović, sentencia del 16 de julio de 2003, pár. 32; y Prosecutor c. Galić, sentencia del 5 de diciembre de 2003, pár. 93.
} 
haber sabido que además constituirían crímenes internacionales. Esta diferenciación entre la tipificación a nivel internacional — que se aborda en este artículo- y la tipificación en derecho interno es de particular relevancia porque, como señala Meron, si bien habitualmente las normas internacionales son implementadas por instituciones y tribunales nacionales que aplican su propio derecho interno, ello no impide que su infracción constituya un crimen internacional (Meron, 1995, p. 563).

De esta manera, además de su ya mencionada consolidación como una norma consuetudinaria en el ámbito del derecho internacional de los derechos humanos durante la década de 1970, el principio de legalidad también evolucionó a nivel normativo y jurisdiccional en el plano del derecho penal internacional, desde su consideración como un "principio de justicia» por el TMI en 1945 hasta su consagración como un principio fundamental en el Estatuto de Roma en 1998.

Es pertinente anotar que el principio de legalidad es aplicable no solo a los individuos como potenciales imputados, sino también a los Estados parte del Estatuto de Roma, sujetos a una serie de obligaciones de cooperación y, eventualmente, a la jurisdicción complementaria de la CPI (Broomhall, 2016, p. 953, pár. 12). Por ello, Catenacci considera que el principio de legalidad es una garantía para los Estados frente a un eventual ejercicio excesivo de la persecución penal internacional que pudiera afectar su soberanía, ya que la normativa penal internacional habría limitado previamente qué conductas son criminales y, por lo tanto, a qué obligaciones se sujeta el Estado (Catenacci, 2003, p. 93).

Históricamente, la aplicación del principio de legalidad en el ámbito internacional ha sido distinta a la de los sistemas penales nacionales, en particular respecto a la necesidad de que la tipificación sea escrita ${ }^{12}$. Su transposición al derecho penal internacional se ha concentrado en la prohibición de la norma penal retroactiva (lex praevia) y a su tipificación específica (lex certa), conforme al artículo 15 del Pacto Internacional de Derechos Civiles y Políticos. Por su parte, con el paso de los años no se habían venido consolidando en el ámbito internacional ni la necesidad de que la criminalización sea escrita (lex scripta) ni la prohibición de la analogía en detrimento del reo (lex stricta) (Raimondo, 2008, p. 107). Sin embargo, como señala Ambos, con el Estatuto de Roma se han reconocido al fin los cuatro aspectos de la máxima nullum crimen sine lege mencionados: lex praevia, lex certa, lex scripta y lex stricta (Ambos, 2013, p. 90).

\footnotetext{
12 Broomhall (2016, p. 957, pár. 23-25) apunta acertadamente las diferencias entre la aplicación del principio de legalidad en el derecho interno de los países con sistemas jurídicos de common law y con sistemas romanogermánicos. Dicho aspecto excede a los confines de este trabajo, pero basta indicar que el desarrollo del principio en el ámbito internacional ha llevado a un consenso e incluso una convergencia entre los juristas de ambas tradiciones jurídicas. Véase también: D’Ascoli, 2011, p. 16.
} 
Sobre la base de los elementos presentados, para efectos de la argumentación planteada en este trabajo el principio de legalidad es plenamente aplicable en lo que respecta a la máxima nullum crimen sine lege desde al menos la década de 1970. Así, es necesario que la conducta esté prevista como un crimen al momento de los hechos y su tipificación debería ser razonablemente específica, i.e., accesible y previsible.

Por ello, cuando en la década de 1970 se produjeron los hechos que fueron juzgados a inicios del siglo XXI en los casos Arancibia Clavel y Simón, los imputados debieron haber estado plenamente protegidos por el alcance del principio de legalidad, que para entonces era parte del núcleo duro del derecho internacional de los derechos humanos como una norma consuetudinaria y como una norma convencional presente en varios tratados universales y regionales de derechos humanos.

\section{Desarrollo histórico de los crímenes de lesa humanidad en el derecho penal internacional}

El desarrollo de la tipificación de los crímenes de lesa humanidad a nivel internacional ha pasado por una evolución que se inicia en 1945, con los tribunales para juzgar los crímenes de los funcionarios de los Estados derrotados en la Segunda Guerra Mundial (Alemania y Japón), y culmina en la década de 1990 con la adopción de los Estatutos para los Tribunales Penales Internacionales para la ex-Yugoslavia (en adelante, el TPIY) ${ }^{13}$ y para Ruanda (en adelante, el TPIR), ${ }^{14}$ y del Estatuto de Roma. Esta evolución tiene como línea transversal el paso del nexo bélico o nexo de guerra - típico del derecho de Núremberg y que requería que las conductas criminales estuvieran vinculadas a una guerra o conflicto armado- al elemento contextual - que requiere que las conductas criminales sean parte de una política de Estado dirigida contra la población civil (o, al menos, contra parte de ella) y de una práctica sistemática o generalizada-.

Para esta sección se omitirán las referencias a los antecedentes del concepto de crímenes de lesa humanidad para concentrarse en el desarrollo de su criminalización a nivel internacional, pues como ha enfatizado Cassese (2008, p. 457), las referencias históricas, que se remontan a Tucídides, «merely constituted homage paid by positive law to natural law. No strictly legal consequence could be assigned to them».

\footnotetext{
${ }^{13}$ El Estatuto del Tribunal Internacional para juzgar a los presuntos responsables de graves violaciones del derecho internacional humanitario cometidas en el territorio de la ex-Yugoslavia a partir de 1991 fue adoptado por el Consejo de Seguridad de la ONU, mediante Resolución 827, de 25 de mayo de 1993, S/RES/827 (1993).

${ }^{14}$ El Estatuto del Tribunal Internacional para Ruanda fue adoptado por el Consejo de Seguridad de la ONU, Resolución 955, de 8 de noviembre de 1994, S/RES/955 (1994).
} 
La pregunta fundamental para la aplicación del tipo penal de los crímenes de lesa humanidad a nivel internacional es qué distingue las conductas hoy tipificadas en el Estatuto de Roma de la CPI de las conductas afines tipificadas en los códigos penales nacionales. Es de especial interés anotar que las conductas subyacentes al elemento contextual y que constituyen en la práctica los crímenes de lesa humanidad - e.g. asesinato, exterminio, esclavitud, entre varias otras recogidas en el artículo 7 del Estatuto de Roma- usualmente son también consideradas criminales en la gran mayoría de sistemas penales nacionales. En tal sentido, ¿por qué se juzgaría a un individuo por crímenes de lesa humanidad bajo el derecho penal internacional y no por asesinato u otra conducta subyacente bajo el derecho penal nacional?

La respuesta se halla en el llamado elemento contextual, es decir, el «elemento internacional» que hace que una conducta criminal devenga un asunto de preocupación internacional y que, por consiguiente, deba ser criminalizada. De acuerdo a Bassiouni, un crimen internacional debe tener necesariamente un «elemento internacional» que permita distinguir los crímenes internacionales de los nacionales, convirtiendo una conducta que es usualmente un delito en el derecho penal nacional en un crimen internacional (Bassiouni, 2011, p. 8).

Una revisión del itinerario de los crímenes de lesa humanidad desde Núremberg hasta el Estatuto de Roma de la CPI muestra cambios en el fundamento empleado para justificar que las conductas criminales subyacentes adquirieran carácter internacional. Como ya se indicó, hacia 1945 se requería el llamado "nexo de guerra» para que las conductas delictivas pudieran ser consideradas crímenes de lesa humanidad. En efecto, conforme al inciso c) del artículo 6 de la Carta del Tribunal de Núremberg, las conductas consideradas como crímenes de lesa humanidad debían haber sido ejecutadas en vinculación con los otros crímenes de competencia del TMI (i.e., crímenes contra la paz o crímenes de guerra) y las víctimas debían haber sido civiles. Los motivos para ello fueron el origen de los crímenes de lesa humanidad en el ámbito del derecho de los conflictos armados (con antecedentes como la cláusula Martens, incorporada en la cuarta convención de La Haya de 1907), lo cual explica los elementos bélico y de protección de la población civil; y la preocupación por que no se infringiera el principio de no intervención, para lo cual el nexo de guerra resultó de suma utilidad (Ambos, 2014, p. 50).

De este modo, para que una conducta sea considerada como un crimen de lesa humanidad, debía cometerse en conexión con delitos contra la paz o con crímenes de guerra («nexo de guerra»), y las víctimas debían ser civiles. Parte de la doctrina sugiere que estas limitaciones no acotaban el tipo penal, si no que más bien solo eran 
precondiciones para el ejercicio de la jurisdicción del TMI ${ }^{15}$. En ese sentido, se habría tratado de aspectos procesales, relativos a la competencia del Tribunal, y no habrían sido parte del tipo penal de los crímenes de lesa humanidad.

Dicha posición "procesalista» es discutible. Por ejemplo, Cassese ha señalado que la tipificación en Núremberg constituyó "derecho nuevo», enfatizando la timidez inicial en su criminalización, sujeta al vínculo de guerra (Cassese, 2008, p. 460). En el mismo sentido, Cryer (2005, p. 40) sugiere que la imputación por crímenes de lesa humanidad tuvo un origen incierto y Bantekas y Nash (2007, pp. 126-127) señalan que, en todo caso, estuvo restringida por su necesaria vinculación con el conflicto armado, conforme al Estatuto de Núremberg.

Pese a ello, un sector de la doctrina considera que antes de la Segunda Guerra Mundial el derecho consuetudinario ya contemplaba los crímenes de lesa humanidad, aunque todavía no se hubiera determinado su contenido (Hall y Ambos, 2016, p. 154, pár. 1), pero esa no parece ser la posición dominante ${ }^{16}$. Por estas consideraciones, Robinson concluye que si bien en 1945 se articuló una primera definición de los crímenes de lesa humanidad, continúa siendo controversial si se trataba de un acto legislativo que creaba un nuevo crimen o de un crimen que ya era parte del derecho consuetudinario (Robinson, 1999, p. 44).

Las posiciones críticas sobre el TMI y su homólogo en Tokio no restan valor a su decisiva importancia para el desarrollo del derecho penal internacional, al ser los primeros tribunales que operaron en el ámbito internacional y por el impulso que los principios y normas involucrados en su creación y aplicados en su jurisprudencia trajeron consigo (Barboza, 1999, p. 34). Con todo, lo relevante para los fines de este trabajo es indagar cuáles eran los componentes del incipiente tipo penal de los crímenes de lesa humanidad en Núremberg, lo que no se aclara con la posición "procesalista». A mayor abundamiento, si se partiera de la premisa de que el nexo de guerra solo se refería a la competencia del TMI, persiste la pregunta de cuál era el contenido de los crímenes de lesa humanidad que el tribunal debería considerar en los respectivos procesos penales, i.e. qué conductas configuraban crímenes de lesa humanidad.

Sobre el particular, existen desarrollos en las décadas siguientes que permiten inferir que pasado el año 1945 no se había llegado a un consenso sobre el tipo penal de

\footnotetext{
15 «Scholars have long debated whether the inclusion of this war nexus in the IMT Charter reflects a substantive limitation on the scope of crimes against humanity or merely a restriction in the jurisdiction of the Nuremberg Tribunal» (McAuliffe de Guzman, 2000, p. 356).

${ }^{16}$ Los propios Hall y Ambos (2016, pp. 154-155, pár. 2) ańaden que, si bien luego de la Segunda Guerra Mundial los crímenes de lesa humanidad fueron reconocidos en varios instrumentos como parte del derecho internacional, a menudo su definición fue "vaga e incoherente».
} 
los crímenes de lesa humanidad en el plano internacional. La práctica subsiguiente a Núremberg en la Alemania de la posguerra parece confirmar un alejamiento del nexo de guerra hacia el llamado «elemento de autoridad» o «elemento de política de Estado», requiriendo «la prueba de participación consciente en procedimientos sistemáticos organizados o aprobados por el gobierno» (Ambos, 2014, p. 51).

Adicionalmente, en el seno de la Comisión de Derecho Internacional (en adelante, la CDI) se consolidó el paso de la exigencia del «nexo de guerra» a la exigencia del «elemento de autoridad» durante la década de 1950. Si bien la CDI mantuvo el nexo de guerra al presentar los llamados principios de Núremberg en $1950^{17}$, este criterio fue ampliado en el proyecto de Código sobre Crímenes contra la Paz y la Seguridad de la Humanidad de 1951 para ir más allá de la guerra ${ }^{18}$. En 1954, en una nueva versión del proyecto, el elemento contextual pasó a requerir que el perpetrador actuase por instigación o con la tolerancia de las autoridades estatales y no se mencionó el nexo de guerra ${ }^{19}$. Esta evolución se basó especialmente en que el elemento internacional que justificaba la persecución internacional, i.e. el derecho de la guerra, estaba siendo progresivamente desplazado en ese rol por la emergencia del derecho internacional de los derechos humanos (Ambos, 2014, p. 52).

Posteriormente hay dos desarrollos de los crímenes de lesa humanidad entre las décadas de 1960 y 1990: la adopción de la Convención sobre la imprescriptibilidad de los crímenes de guerra y de los crímenes de lesa humanidad y una serie de sentencias en los tribunales nacionales de varios Estados contra exfuncionarios de la Alemania nazi. El inciso b) del artículo I de la Convención, adoptada el 26 de noviembre de 1968 y en vigor desde el 1 de noviembre de 1970, presenta dos aspectos de singular importancia: primero, establece la imprescriptibilidad de los crímenes de lesa humanidad, incluyendo conductas cometidas en guerra o en tiempos de paz, y, segundo, señala que no es importante en qué momento fueron cometidos, incorporando de este modo una aparente retroactividad sobre la imprescriptibilidad.

El primer aspecto es de especial interés, porque permite sostener que para 1968 se venía consolidando la posición de que no se requería el nexo de guerra para que se configurase un crimen de lesa humanidad. El segundo es problemático porque la posibilidad de aplicar retroactivamente la imprescriptibilidad restringe los derechos del imputado y vulnera el principio de legalidad. Aun si se considerase que los crímenes de lesa humanidad ya existían como un crimen internacional en la década de 1960

\footnotetext{
${ }_{17}$ Principio VI, c), de los Principios de Núremberg, Yearbook of the International Law Commission 1950, vol. 2, p. 377. ${ }^{18}$ Artículo 2.10 del Código sobre Crímenes contra la Paz y la Seguridad de la Humanidad, Yearbook of the International Law Commission 1951, vol. 2, p. 136.

${ }^{19}$ Artículo 2.11, del Código sobre Crímenes contra la Paz y la Seguridad de la Humanidad, Yearbook of the International Law Commission 1954, vol. 2, pp. 151-152.
} 
—lo que es objeto de análisis en esta sección—, es evidente que las condiciones de su persecución deberían también estar sujetas al principio de legalidad, requisito que, como ya se vio en la sección anterior, se venía consolidando en esa década, especialmente tras la adopción del Pacto Internacional sobre Derechos Civiles y Políticos en 1966.

Respecto al segundo desarrollo, en las décadas siguientes a la Segunda Guerra Mundial hubo una serie de sentencias en los tribunales nacionales de varios Estados sobre presuntos crímenes de lesa humanidad cometidos por exfuncionarios de la Alemania nazi. En los años inmediatamente siguientes a Núremberg hasta 1951, una serie de tribunales a cargo de las potencias aliadas que ocupaban Alemania aplicó la Ley del Consejo de Control Aliado No. 10 de 19 de enero de 1946, bajo la cual se procesó a varios individuos - entre otros, médicos, funcionarios públicos y empresarios alemanes - por su participación en actividades accesorias a las juzgadas por el TMI que contribuyeron a la perpetración de diversos crímenes en la Alemania nazi. La Ley, que otorgó jurisdicción a los tribunales a cargo de los aliados, fue promulgada al amparo de la transferencia de poderes soberanos del Estado alemán a las potencias ocupantes, en virtud de la rendición incondicional de Alemania al fin de la Segunda Guerra Mundial (Barboza, 1999, p. 37) ${ }^{20}$. Por ello, es difícil sostener que dicha Ley sea evidencia de derecho penal internacional, aunque es de particular interés la eliminación del nexo de guerra para los crímenes de lesa humanidad. Con todo, como señala Lamb, ninguna de las sentencias es jurídicamente satisfactoria, pues su argumentación para concluir que el principio de legalidad no era aplicable fue «contradictoria y débil» (Lamb, 2002, p. 739). La Ley fue abolida el 30 de mayo de 1956 por la legislación alemana relativa al término de la ocupación aliada, lo que constituye evidencia adicional de su carácter de derecho creado por las potencias ocupantes y no de derecho penal internacional. Además, es sintomático de su contingencia que el derecho penal alemán recién incorporó el «derecho de Núremberg» en 2002, con la entrada en vigor del Código alemán de derecho penal internacional (Ambos, 2013, pp. 7-8).

El caso más conocido de un exfuncionario nazi procesado por crímenes de lesa humanidad fue el de Adolf Eichmann, sentenciado a muerte por la Corte Distrital de Jerusalén el 12 de diciembre de 1961 por su responsabilidad en la implementación de la «solución final» a «la cuestión judía», bajo los tipos penales de genocidio y crímenes de lesa humanidad ${ }^{21}$. Como señala Ambos, el caso Eichmann tiene especial importancia porque el Estado de Israel no existía cuando se cometieron las conductas

\footnotetext{
20 Véase también: United States - France - Great Britain - Soviet Union. (1945). Declaration Regarding the Defeat of Germany and the Assumption of Supreme Authority with Respect to Germany and Supplementary Statements, pp. 171-172.

21 Las referencias a los casos Eichmann, Barbie, Touvier, Finta y Demjanjuk, véase en: Ambos, 2013, pp. 8-9.
} 
delictivas, de modo que la jurisdicción israelí no se pudo haber basado en el «derecho de los vencedores» de la Segunda Guerra Mundial (Ambos, 2013, p. 8). Con todo, el caso Eichmann se decidió sin que hubiera un tipo penal para los crímenes de lesa humanidad en el derecho penal internacional.

Un caso de particular notoriedad por las peripecias en la extradición del procesado fue el de Klaus Barbie, quien fue juzgado en contumacia por crímenes de guerra cometidos cuando fue jefe de la Gestapo en Lyon durante la ocupación alemana de Francia y condenado a muerte por un tribunal militar lionés. Posteriormente se refugió en Bolivia y, tras largas y complicadas negociaciones, fue extraditado a Francia en 1983 donde fue finalmente sentenciado en Lyon, el 4 de julio de 1987, en un proceso nuevo por crímenes de lesa humanidad.

Otros casos de relevancia fueron la condena a prisión perpetua de Paul Touvier, sentenciado el 20 de abril de 1994 en Versalles, Francia; la absolución de Imre Finta por la Corte Suprema de Canadá el 24 de marzo de 1994; y la saga de los procesos contra John Demjanjuk, "Iván el Terrible», quien murió antes de que se decidiera sobre su apelación a la sentencia de la Corte del Distrito de Múnich, Alemania, del 15 de mayo de 2011.

Los casos Eichmann, Barbie, Touvier, Finta y Demjanjuk tienen en común tres aspectos: se refieren a atrocidades cometidas por funcionarios de la Alemania nazi, se siguieron en tribunales domésticos y se basaron en normativa de derecho interno, que en cierta manera buscaba reflejar los avances en la doctrina jurídica internacional. Por ello, es sumamente discutible que dichos precedentes puedan ser considerados como evidencia de la criminalización a nivel internacional de los crímenes de lesa humanidad, además de que la creación y aplicación de la normativa doméstica correspondiente a cada uno de ellos presenta serios problemas en cuanto a su compatibilidad con el principio de legalidad.

En la mayor parte de los casos mencionados, los tribunales sostuvieron la inaplicabilidad del principio de legalidad sobre la base de la jurisprudencia del TMI, coincidiendo en que la Carta de Núremberg era declaratoria del derecho internacional preexistente respecto a los crímenes de lesa humanidad, por lo que su tipificación no era ni derecho nuevo ni derecho ex post facto. Así, como señala Lamb, los insuficientes argumentos del TMI cobraron nueva relevancia por su continua repetición (Lamb, 2002, p. 740). Sin embargo, desde un punto de vista estrictamente jurídico, los defectos de las sentencias de Núremberg sobre la tipificación de los crímenes de lesa humanidad subsisten, por lo que no parece razonable concluir que las reiteradas referencias a su autoridad como precedentes los valida. Como sostiene contundentemente Bassiouni (2011): 
[A]ll national prosecutions undertaken after 1946 took the same position, and none reopened the question, as if the accumulation of time and precedents relying on the IMT's judgments had cured all possible legal defects. This leads to the legally incongruous conclusion that reiteration of the same argument confirms its validity. [...] [I] $\mathrm{t}$ can hardly be said, from a jurisprudential point of view, that a precedent like the IMT's judgment on the question of ex post facto can be validated with respect to itself only by the subsequent reaffirmation of others. Surely a better legal case could have been made by the IMT, and subsequent decisions could have at least attempted to cure its defects by buttressing the arguments in support of legality with stronger and more convincing arguments. (pp. 356-357)

Por dichas consideraciones, si bien estas sentencias de tribunales nacionales pueden ser entendidas como avances progresivos en la compleja tarea de consolidar el tipo penal de los crímenes de lesa humanidad, su influencia en el derecho penal internacional se ve reducida por las características propias del derecho internacional, como la ausencia de un legislador y una judicatura centralizados. Adicionalmente, teniendo en cuenta que antes de los estatutos del TPIY, el TPIR y la CPI los crímenes de lesa humanidad no fueron codificados a nivel internacional, las sentencias mencionadas podrían eventualmente ser consideradas como contribuciones al afianzamiento de una costumbre internacional. Sin embargo, debe recordarse que, al tratarse de decisiones de derecho interno, es más difícil que puedan ser tratadas como evidencia de la opinio iuris de la comunidad internacional.

En este sentido, sin darle mayor relevancia a las sentencias de tribunales nacionales ya mencionadas, Robinson ha enfatizado que, luego de los procesos de Núremberg, el siguiente hito en la tipificación de los crímenes de lesa humanidad a nivel internacional fue la adopción en el Consejo de Seguridad de la ONU, cincuenta años después, de los estatutos de los tribunales ad hoc para la ex-Yugoslavia y para Ruanda, en 1993 y 1994, respectivamente (Robinson, 1999, p. 45). Esta falta de desarrollos previos a los tribunales ad hoc es tan notoria que Bantekas y Nash han señalado que desde Núremberg no había aparecido ninguna nueva definición internacional de los crímenes de lesa humanidad antes del TPIY (Bantekas y Nash, 2007, pp. 126-127).

Por ello, se puede concluir que antes de los estatutos para la ex-Yugoslavia y Ruanda no se había culminado con la tipificación de los crímenes de lesa humanidad en el derecho penal internacional. Con todo, es oportuno indagar si es posible identificar en los mencionados estatutos los elementos para una tipificación de los crímenes lesa humanidad que satisfaga los requisitos de accesibilidad y previsibilidad planteados por el TEDH y ya presentados en este trabajo.

Al respecto, los estatutos para la ex-Yugoslavia y para Ruanda tienen importantes diferencias en su elemento contextual, las cuales recién serían superadas con la tipificación universal e inequívoca del Estatuto de Roma. Sin ánimo de hacer una 
comparación exhaustiva entre ambos estatutos, es evidente que el retorno del nexo de guerra en el estatuto para la ex-Yugoslavia significó un sorpresivo retroceso en la tipificación de los crímenes de lesa humanidad ${ }^{22}$, que debió ser superado a través de la jurisprudencia del TPIY ${ }^{23}$. Por su parte, en el estatuto para Ruanda no se incluyó el nexo de guerra ni se hizo referencia a conflictos armados, sino que se incorporaron como una novedad los requisitos de "ataque generalizado y sistemático" para el elemento contextual ${ }^{24}$, destacados como «la única aproximación correcta» (Ambos, 2014, p. 55) y que serían eventualmente incorporados en el tipo penal adoptado en el Estatuto de Roma. Adicionalmente, la intención discriminatoria «por razones de nacionalidad, políticas, étnicas, raciales o religiosas» establecida para Ruanda fue también una novedad, aunque finalmente fue descartada en la jurisprudencia del TPIR y en la negociación del Estatuto de Roma.

La especial relevancia de estas diferencias es que son sintomáticas de la falta de consenso que existía a mediados de la década de 1990 sobre el contenido del tipo penal de los crímenes de lesa humanidad, particularmente sobre su elemento contextual. Este es un punto fundamental que expone, desde el punto de vista de los imputados, las dificultades para que el tipo penal pudiera satisfacer el estándar de accesibilidad y previsibilidad. De hecho, cupo a los jueces culminar la tarea de abandonar el nexo de guerra para concentrarse en los requisitos de «ataque generalizado y sistemático", por lo que la innovadora jurisprudencia de los tribunales ad hoc fue la base para la redacción del artículo 7.1 del Estatuto de Roma, en el cual recién se tipifican los crímenes de lesa humanidad en el derecho penal internacional. De hecho, la jurisprudencia de los tribunales ad hoc contribuyó decisivamente a que, en la determinación de los elementos contextuales del tipo penal de los crímenes de lesa humanidad, los requisitos de «ataque generalizado y sistemático» fueran interpretados como una disyuntiva y no como una conjunción ${ }^{25}$.

\footnotetext{
22 El artículo 5 del Estatuto para el TPIY seńala, respecto de los crímenes de lesa humanidad: «El Tribunal Internacional está habilitado para juzgar a los presuntos responsables de los siguientes crímenes cuando estos han sido cometidos en el curso de un conflicto armado, de carácter internacional o interno, y dirigidos contra cualquier población civil».

23 «[I]t is now a settled rule of customary international law that crimes against humanity do not require a connection to international armed conflict. [...] [T] he Security Council may have defined the crime in Article 5 more narrowly than necessary under customary international law» (Tribunal Penal Internacional para la ex-Yugoslavia, Prosecutor c. Tadić, sentencia del 2 de octubre de 1995, pár. 141).

$24 \mathrm{El}$ artículo 3 del Estatuto para el TPIR seńala, respecto de los crímenes de lesa humanidad: «El Tribunal Internacional para Ruanda tendrá competencia para enjuiciar a los presuntos responsables de los crímenes que se seńalan a continuación, cuando hayan sido cometidos como parte de un ataque generalizado o sistemático contra la población civil por razones de nacionalidad o por razones políticas, étnicas, raciales o religiosas». Énfasis añadido.

25 Pese a que en el Estatuto para la ex-Yugoslavia no se incluyeron los requisitos de ataque generalizado y sistemático, el TPIY sostuvo: «[I]t is therefore the desire to exclude isolated or random acts from the notion of crimes against humanity that led to the inclusion of the requirement that the acts must be directed against a civilian 'population',
} 
Si a inicios de la década de 1990 el propio Consejo de Seguridad de la ONU, contando con la asistencia de especialistas en derecho penal internacional, elaboró los estatutos para la ex-Yugoslavia y para Ruanda con tan importantes diferencias entre ellos, es sostenible que estos no superarían el estándar de accesibilidad y previsibilidad, por lo que los imputados tendrían serias dificultades para conocer que su conducta era criminal. Por ello, el principio de legalidad debería haber podido ser alegado como una defensa frente a la persecución penal del TPIY y del TPIR, por lo menos respecto de los crímenes de lesa humanidad. Evidentemente, esto no es óbice para la persecución penal en los tribunales nacionales, siempre que los crímenes de lesa humanidad ya hubieran estado tipificados en la normativa penal doméstica.

Schabas (2000, p. 538) ha sostenido, problemáticamente, que luego de Núremberg los imputados deberían estar suficientemente al tanto de que los crímenes de guerra y los crímenes de lesa humanidad acarrean las más severas penas, por lo que ya no pueden alegar defensas sobre la base del principio de legalidad. Sin embargo, esta línea argumentativa no toma en cuenta que los imputados no tenían cómo conocer cuáles eran las conductas que constituían crímenes de lesa humanidad, pues, como se ha explicado en este trabajo, su elemento contextual recién fue abordado en la elaboración de los estatutos para el TPIY y el TPIR, con sustanciales diferencias, y establecido inequívocamente en el Estatuto de Roma. Asimismo, de modo complementario, las conductas subyacentes tampoco estaban enumeradas. En esa medida, es difícil sustentar que el derecho de Núremberg sea suficiente para satisfacer las exigencias del aforismo nullum crimen sine lege o el estándar de accesibilidad y previsibilidad.

De este modo, la tipificación de los crímenes de lesa humanidad en los estatutos para la ex-Yugoslavia y Ruanda no habría logrado cumplir con el criterio jurisprudencial adoptado por el TEDH para el principio de legalidad, que requiere la «accesibilidad» y «previsibilidad» del tipo penal. Este criterio sí estaría cumplido con la adopción del texto del Estatuto de Roma que crea la CPI, recién a partir del cual hay certeza sobre el tipo penal de los crímenes de lesa humanidad.

Para fines de la exploración histórica de la criminalización de los crímenes de lesa humanidad, las diferencias entre los estatutos de los tribunales ad hoc resultan suficientes para establecer que recién en algún punto entre sus primeras sentencias y la

\footnotetext{
and either a finding of widespreadness [...] or systematicity (Tribunal Penal Internacional para la ex-Yugoslavia, Prosecutor c. Tadić, sentencia del 7 de mayo de 1997, pár. 648)».

Por su parte, el TPIR interpretó los mencionados requisitos, que sí habían sido previstos en su Estatuto, en el sentido de que no era necesario que se dieran conjuntamente: «The Chamber considers that it is a prerequisite that the act must be committed as part of a widespread or systematic attack and not just a random act of violence. The act can be part of a widespread or systematic attack and need not be part of both (Tribunal Penal Internacional para Ruanda, Prosecutor c. Akayesu, sentencia del 2 de septiembre de 1998, pár. 579)».
} 
adopción del texto del Estatuto de Roma culmina el derrotero, que duró 50 años, en el cual se consolida una tipificación para los crímenes de lesa humanidad en el derecho penal internacional, en paralelo a la ya reseñada consagración del principio de legalidad como parte del núcleo duro del derecho internacional de los derechos humanos.

Adicionalmente, parece difícil sostener que haya existido una costumbre internacional que tipificara los crímenes de lesa humanidad antes de, por lo menos, la jurisprudencia de los tribunales ad hoc. Hay autores que admiten la costumbre como una fuente suficiente para la tipificación de los crímenes de lesa humanidad, como Ambos (2014, p. 47), quien sostiene que es posible afirmar que los crímenes de lesa humanidad ya eran parte del derecho consuetudinario antes de los procesos de Núremberg y Cassese (2006, pp. 417-418), quien señala que los crímenes de lesa humanidad estaban ya prohibidos por una norma general de derecho internacional que había cristalizado — por lo tanto, era consuetudinaria— poco después de los procesos de Núremberg ${ }^{26}$.

Sin embargo, esos autores no muestran ni la existencia de una práctica recurrente y generalizada a nivel internacional ni la correlativa «conciencia de obligatoriedad» sobre dicha práctica, elementos necesarios para que surja una costumbre internacional. Al respecto, parece difícil sustentar que la práctica internacional previa al TPIY y al TPIR, con solo unos pocos procesos judiciales asociados a exfuncionarios y exdirigentes nazis en el TMI y en tribunales nacionales, pueda haber llevado al establecimiento de un tipo penal para los crímenes de lesa humanidad en derecho internacional. Por ello, comparto la posición de Robinson de que, si bien el proceso de tipificación de los crímenes de lesa humanidad como derecho consuetudinario se inicia en Núremberg, el mismo recién concluye, con dudas e incoherencias, con los tribunales ad hoc, que "marcaron el camino" para el desarrollo de un corpus de jurisprudencia internacional que guio a las delegaciones que participaron en la negociación del Estatuto de Roma (Robinson, 1999, p. 45).

En particular, los tribunales para la ex-Yugoslavia y Ruanda tuvieron desarrollos sobre la base del derecho consuetudinario, pero en la argumentación de sus sentencias fundacionales no se sustentaron los elementos material ni subjetivo de las costumbres invocadas, sino que se las asumió como dadas. Si, como afirma Lamb, las sentencias de los tribunales ad hoc frecuentemente parecen ser declaratorias de principios consuetudinarios nacientes, que previamente no habían sido expresados (Lamb, 2002, p. 745), se debe recordar que el derecho consuetudinario requiere como mínimo la verificación de conductas previas con conciencia de obligatoriedad.

\footnotetext{
26 Sin embargo, Cassese (2008, p. 460) sostiene que parece más probable que, respecto a los crímenes de lesa humanidad, el Estatuto de Núremberg constituyera «derecho nuevo», en lugar de haber cristalizado o codificado una norma naciente de derecho internacional general.
} 
Por ello, parece difícil aceptar jurídicamente la validez de "principios consuetudinarios» que "no habían sido expresados previamente», pese a que los tribunales ad hoc han recurrido a ellos con frecuencia.

$\mathrm{Al}$ respecto, comparto la apreciación de Lamb de que la definición de los crímenes internacionales por los tribunales ad hoc ha sido más bien emotiva, incluso de lege ferenda (Lamb, 2002, p. 746). Con todo, la lex ferenda tiene un carácter paradójico, pues si bien por definición no es parte del derecho positivo, no se trata de un mero concepto antitético que pueda ser definido como "aquello que no es derecho", sino que se refiere a algo que en cierto sentido "debería ser derecho" (Thirlway, 2001, p. 4). Sin embargo, el considerar que algo debería ser derecho no constituye evidencia de que efectivamente lo sea (Akehurst, 1975, p. 5; CIJ, 1969, p. 38, pár. 62). Dicho esto, es innegable que la jurisprudencia, interpretación e incluso integración del derecho de los tribunales ad hoc han jugado un rol fundamental en el desarrollo y consolidación del derecho penal internacional, que a inicios de la década de 1990 todavía se encontraba en una etapa embrionaria.

La tipificación de los crímenes de lesa humanidad en el derecho penal internacional fue completada sin duda alguna con la adopción del texto del Estatuto de Roma, un tratado de alcance universal. Aun así, es de suma pertinencia recordar que en las negociaciones del Estatuto de Roma se hizo evidente que para entonces, luego del TPIY y del TPIR, no existía una definición generalmente aceptada del contenido de los crímenes de lesa humanidad y que había incongruencias en los precedentes que buscaron definirlos (Robinson, 1999, p. 43, nota 4). Sin ánimo de ahondar en las negociaciones del Estatuto de Roma, cabe reiterar que si los propios especialistas que participaron en ellas debieron trabajar arduamente para consensuar un tipo penal que recogiera los avances jurisprudenciales de los tribunales ad hoc y los desarrollos doctrinarios, parece sumamente difícil sostener que un potencial imputado se podía encontrar en condiciones de conocer qué conductas eran consideradas por el derecho penal internacional como crímenes de lesa humanidad, vulnerándose así el principio de legalidad y el estándar de accesibilidad y previsibilidad.

\section{Conclusiones}

Como se mencionó en la introducción, el objetivo fundamental de este trabajo es mostrar que existe un dilema entre la persecución de las atrocidades cometidas antes de la tipificación de los crímenes de lesa humanidad y el conflicto que dichas acciones suponen con el principio de legalidad, especialmente bajo las nociones de accesibilidad y previsibilidad planteadas por el TEDH para la aplicación de la máxima nullum crimen sine lege. 
Parece ser más sencillo demostrar que el principio de legalidad se ha visto fortalecido con el paso de las décadas desde 1945, al punto de que es ampliamente reconocido como parte del núcleo duro del derecho internacional de los derechos humanos. Por su parte, es más difícil demostrar el itinerario complementario de la tipificación de los crímenes de lesa humanidad en el derecho penal internacional.

Con todo, espero que esta indagación sobre la historia de la tipificación de los crímenes de lesa humanidad en el plano internacional —en particular el cuestionamiento a su pretendido carácter consuetudinario previo a los tribunales ad hoc y las consecuencias de las diferencias entre los estatutos del TPIY y del TPIR — permita evaluar transversalmente si antes del Estatuto de Roma el tipo penal de los crímenes de lesa humanidad cumplía con los criterios de accesibilidad y previsibilidad para los imputados, i.e., si los imputados podían conocer razonablemente qué conductas constituían crímenes de lesa humanidad conforme al derecho penal internacional, ya sea a través de normas escritas, normas consuetudinarias o normas creadas jurisprudencialmente.

$\mathrm{Si}$ ambas conclusiones se sostienen, es posible afirmar que las referencias a los procesos de Núremberg, al derecho consuetudinario y a normas de derecho internacional con carácter de ius cogens son insuficientes para superar el dilema de cómo procesar a los imputados por crímenes de lesa humanidad respetando el principio de legalidad. Al respecto, si los jueces de la Corte Suprema de Justicia de la Nación argentina consideraron que en casos como Arancibia Clavel y Simón el dilema estaba solucionado sobre las fuentes mencionadas, esa posición es equivocada.

En este punto, es de suma pertinencia lo indicado por Cassese sobre la diferencia entre la ponderación del principio de legalidad durante los procesos de Núremberg con la de las décadas siguientes, en la cual se aprecia el paso de una doctrina de justicia a una de legalidad que la Corte Suprema de Justicia de la Nación argentina no contempló:

The International Military Tribunal clearly embraced the doctrine of substantive justice (whereby any conduct that is socially harmful or causes danger to society should be prohibited and punished, whether or not that conduct had already been criminalized by law at the moment it had been taken), as opposed to that of strict legality (postulating that a person may only be held criminally liable if at the time he commits a certain act, that act is clearly and specifically criminalized by law). Since then, however, the latter doctrine has also gradually permeated international law and taken roots in it. This occurred through the adoption of international treaties on human rights $[\ldots]$, which have imposed the nullum crimen principle in its strict dimension on states, when conducting national trials. From there the principle gradually expanded, to a large extent, to international trials. (Cassese, 2006, pp. 416-417) 
$\mathrm{Al}$ respecto, parece recomendable que en cada jurisdicción doméstica haya una toma de posición sobre este problema, atendiendo a las dos constataciones que este trabajo ofrece:

a. El célebre dictum del TMI sobre el principio de legalidad como una mera aspiración de justicia no se refería a los crímenes de lesa humanidad y, además, es difícilmente aplicable a conductas posteriores luego del reconocimiento de dicho principio como parte del núcleo duro del derecho internacional de los derechos humanos; $y$,

b. La decisión de procesar retroactivamente por crímenes de lesa humanidad, i.e. cometidos previamente a su tipificación, ya sea en sede doméstica o internacional, debe ser adoptada con sumo cuidado porque implica vulnerar el principio de legalidad.

El abandono de la necesidad de justificar la inaplicación del principio de legalidad en aras de evitar la impunidad de los crímenes de lesa humanidad, particularmente sobre la base del incipiente derecho penal internacional de Núremberg, es una grave deficiencia jurídica cuyo resultado es la afectación de los derechos humanos del imputado, dejando además dudas sobre la legitimidad y justicia de las condenas correspondientes. La determinación de si es deseable afectar los derechos humanos del imputado por las atrocidades que cometió es un dilema fundamental en un Estado de derecho, pero es necesario comprender que las persecuciones penales en las que se aplica retroactivamente el tipo penal de los crímenes de lesa humanidad suponen inherentemente un conflicto con el principio de legalidad.

Si bien las sentencias condenatorias en procesos judiciales como Simón y Arancibia Clavel podrán haber sido celebradas por ciertos sectores de la sociedad, particularmente los familiares de las víctimas, "un ideal de justicia» requiere que se evalúe si con esas condenas se privó a los imputados de una de las garantías mínimas de derecho penal sin una apropiada justificación jurídica. A menos, claro está, que se abra la puerta a una posibilidad difícilmente sostenible en una democracia liberal y respetuosa del Estado de derecho: considerar que los imputados por crímenes de lesa humanidad no tienen los mismos derechos que el resto de los ciudadanos.

\section{Referencias bibliográficas}

Akehurst, M. (1975). Custom as a Source of International Law, British Yearbook of International Law, 47(1), 1-53. https://doi.org/10.1093/bybil/47.1.1

Ambos, K. (2013). Treatise on International Criminal Law. Volume I: Foundations and General Part. Oxford: Oxford University Press. https://doi.org/10.1093/ law/9780199657926.001.0001 
La relación entre el principio de legalidad en derecho penal internacional y la tipificación internacional... 207

Ambos, K. (2014). Treatise on International Criminal Law. Volume II: The Crimes and Sentencing. Oxford: Oxford University Press.

Arnold, J., Karsten, N., y Kreicker, H. (2003). The German Border Guard Cases before the European Court of Human Rights, European Journal of Crime, Criminal Law and Criminal Justice, 11(1), 67-92. https://doi.org/10.1163/157181703100383534

Bantekas, I., y Nash, S. (2007). International Criminal Law. Londres/Nueva York: Routledgel Cavendish.

Barboza, J. (1999). International Criminal Law. Recueil des Cours, 278, 9-199. https://doi. org/10.1163/ej.9789041113962.009-199

Bassiouni, M.Ch. (2011). Crimes Against Humanity. Historical Evolution and Contemporary Application. Cambridge: Cambridge University Press, 2011. https://doi.org/10.1017/ CBO9780511976537

Broomhall, B. (2016). Article 22: Nullum crimen sine lege. En O. Triffterer y K. Ambos (eds.), The Rome Statute of the International Criminal Court. A Commentary (pp. 144-178). Munich/Oxford/Baden-Baden: C.H. Beck - Hart - Nomos. https://doi. org/10.5771/9783845263571-950

Brownlie, I. (1963). International Law and the Use of Force by States. Oxford: Oxford University Press. https://doi.org/10.1093/acprof:oso/9780198251583.001.0001

Cassese, A. (2006). Balancing the Prosecution of Crimes against Humanity and Non-Retroactivity of Criminal Law: The Kolk and Kislyiy v. Estonia Case before the ECHR. Journal of International Criminal Justice, 4(2), 410-418. https://doi. org/10.1093/jicj/mql016

Cassese, A. (2008). Crimes against Humanity: Comments on Some Problematic Aspects. En A. Cassese. The Human Dimension of International Law (pp. 457-474). Oxford: Oxford University Press. https://doi.org/10.1093/acprof:oso/9780199232918.003.0023

Catenacci, M. (2003). The Principle of Legality. En F. Lattanzi y W.A. Schabbas (eds.), Essays on the Rome Statute of the International Criminal Court (pp. 85-102). Ripa di Fagnano Alto: Editrice il Sirente.

Corte Internacional de Justicia - CIJ (1969). Caso de la plataforma continental en el Mar del Norte. ICJ Reports.

Cryer, R. (2005). Prosecuting International Crimes. Selectivity and the International Criminal Law Regime. Cambridge: Cambridge University Press. https://doi.org/10.1017/ CBO9780511494161

D'Ascoli, S. (2011). Sentencing in Criminal International Law: The UN ad hoc Tribunals and Future Perspectives for the ICC. Oxford: Hart.

Gallant, K.S. (2009). The Principle of Legality in International and Comparative Criminal Law. Cambridge: Cambridge University Press. https://doi.org/10.1017/ CBO9780511551826

Garibian, S. (2010). Le recours au droit international pour la répression des crimes du passé: Regards croisés sur les affaires Touvier (France) et Simón (Argentine). Annuaire Français de Droit International, 56, 197-215. https://doi.org/10.3406/afdi.2010.4607 
Hall, C. y Ambos, K. (2016). Crimes Against Humanity. En O. Triffterer y K. Ambos (eds.), The Rome Statute of the International Criminal Court. A Commentary (pp. 144-178). Munich/Oxford/Baden-Baden: C.H. Beck - Hart - Nomos.

Kelsen, H. (1947). Will the Judgment in the Nuremberg Trial Constitute a Precedent in International Law? International Law Quarterly, 1(2), 153-171.

Lamb, S. (2002). Nullum Crimen, Nulla Poena Sine Lege in International Criminal Law. En A. Cassese, P. Gaeta y J.R.W.D. Jones (eds.), The Rome Statute of the International Criminal Court: A Commentary (pp. 733-766). Oxford: Oxford University Press.

Legarre, S. (2006). Crimes against Humanity, Reasonableness and the Law: the Simon Case in the Supreme Court of Argentina. Chinese Journal of International Law, 5(3), 511-553. https://doi.org/10.1093/chinesejil/jml041

Liszt, F. (2007). The Rationale for the Nullum Crimen Principle. Journal of International Criminal Justice, 5(4), 1009-1013. https://doi.org/10.1093/jicj/mqm054

McAuliffe de Guzman, M. (2000). The Road From Rome: The Developing Law of Crimes Against Humanity. Human Rights Quarterly, 22(1), 335-403. https://doi.org/10.1353/ hrq.2000.0023

Meron, T. (1995). Criminalization of Internal Atrocities. American Journal of International Law, 89(3), 554-577. https://doi.org/10.2307/2204173

ONU - Organización de Naciones Unidas. (3 de mayo de 1993). Report of the Secretary General Pursuant to Paragraph 2 of Security Council Resolution 808 (1993). UN Doc. S/25704. Nueva York. Recuperado de https://www.securitycouncilreport.org/ un-documents/document/icty-s-25704-statute-re808-1993-en.php

ONU - Organización de Naciones Unidas. (1996). Report of the Preparatory Committee on the Establishment of an International Criminal Court, UN GAOR, 51 a sesión, Supp. No. 22, UN Doc. A/51/22 (1996). Nueva York. Recuperado de https://www.legal-tools. org/doc/e75432/pdf/

Raimondo, F.O. (2008). General Principles of Law in the Decisions of International Criminal Courts and Tribunals. Leiden: Martinus Nijhoff. https://doi.org/10.1163/ ej.9789004170476.i-214

Robinson, D. (1999). Defining 'Crimes Against Humanity' at the Rome Conference, American Journal of International Law, 93(1), 43-57. https://doi.org/10.2307/2997955

Schabas, W.A. (2000). Perverse Effects of the Nulla Poena Principle: National Practice and the Ad Hoc Tribunals. European Journal of International Law, 11(3), 521-539. https:// doi.org/10.1093/ejil/11.3.521

Schabas, W.A. (2015). The European Convention on Human Rights. A Commentary. Oxford: Oxford University Press.

Schwelb, E. (1946) Crimes against Humanity. British Yearbook of International Law, 23, 178-226.

Sévane, G. (2010). Le recours au droit international pour la répression de crimes du passé. Regards croisés sur les affaires Touvier (France) et Simón (Argentine), Annuaire Français de Droit International, 56, 197-215. https://doi.org/10.3406/afdi.2010.4607 
La relación entre el principio de legalidad en derecho penal internacional y la tipificación internacional... 209

Thirlway, H. (2001). Reflections on Lex Ferenda, Netherlands Yearbook of International Law, 32, 3-26. https://doi.org/10.1017/S0167676800001148

Tribunal Militar Internacional de Núremberg (1947). Trial of the Major War Criminals before the International Military Tribunal: Nuremberg 14 November 1945 - 1 October 1946. Núremberg. Recuperado de https://www.loc.gov/rr/frd/Military_Law/pdf/NT_ Vol-I.pdf

United States - France - Great Britain - Soviet Union. (1945). Declaration Regarding the Defeat of Germany and the Assumption of Supreme Authority with Respect to Germany and Supplementary Statements. The American Journal of International Law, 39(3), Supplement Official Documens, 171-178. https://doi.org/10.2307/2213921

Recibido: 30 de abril de 2019 Aprobado: 8 de agosto de 2019 